\title{
Influence of Monitoring and Evaluation Planning on the Performance of Government Programs: A Case of Uganda Women Entrepreneurship Program in Busoga Sub-Region, Uganda
}

\author{
Mbaziira Hassan*, \\ Dr. Naomi Nduta Njoroge** \\ "Monitoring, Evaluation, Accountability \& Learning (MEAL) Specialist; Uganda Women Entrepreneurship Programme (UWEP) \\ **Department of Social and Development Studies, School of Social Sciences, Mount Kenya University \\ DOI: 10.29322/IJSRP.11.10.2021.p11816 \\ http://dx.doi.org/10.29322/IJSRP.11.10.2021.p11816
}

\begin{abstract}
The phenomenon of performance of government programs is extensively researched across the globe. However, the influence of monitoring and evaluation planning on the performance of government programs remains a grey area. The study sought to examine the influence of monitoring and evaluation planning on the performance of government programs using a case study of Uganda Women Entrepreneurship Program in Busoga, Uganda. Using a cross-sectional survey design, quantitative and qualitative date were collected from a random sample of UWEP beneficiary groups and a non-random sample of UWEP supervisors from Jinja, Iganga and Kamuli districts. The data was analyzed quantitatively and qualitatively. The findings indicated a Pearson's correlation coefficient of 0.755 with a corresponding probability that was less than $5 \%$. The study concluded that monitoring and evaluation planning was a significant factor in the performance of government programs more so, the Uganda Women Entrepreneurship Program in Busoga.
\end{abstract}

Index Terms: Monitoring and evaluation planning, program performance, Uganda Women Entrepreneurship Programme, Busoga, Uganda.

\section{Introduction}

Monitoring and evaluation (M\&E) is globally recognized and widely adopted as a tool for ensuring optimal program/project performance. The United States of America has in place well-developed and functioning M\&E legislations, institutions and practices that partially explain the country's relatively superior national programs and service delivery systems (Mark \& Pfeiffer, 2011). Benchmarking on experiences of the United States, countries in Europe such as France, Great Britain, Sweden, Denmark, Netherlands, Switzerland, Spain, and Italy also have well-developed M\&E systems that underlie their enviable national service delivery programs (Schoenefeld, Schulze, Hildén, \& Jordan, 2019). In Africa, demand for M\&E has been growing over the last three decades, and is projected to grow even further following the realization by development planners and implementers of the tool's importance in fostering desirable national development outcomes (Kusek \& Rist, 2004). In Uganda, the government highly recognizes the importance of $M \& E$ in ensuring effective and efficient management of public programs/projects evidenced by the recent enactment of the National Policy on Public Sector Monitoring and Evaluation. The policy seeks to foster optimal performance of government programs and projects (Uganda Office of Prime Minister, 2011).

One of the perquisites of optimal performance of government programs is monitoring and evaluation (M\&E) planning (Nyonje, Ndunge, \& Mulwa, 2012). Proper M\&E planning entails the following: existence of a mechanism for coordinating M\&E of UWEP activities, existence of a clear procedure for implementing M\&E of UWEP activities, assignment of tasks \& responsibilities for M\&E of UWEP activities, and availability of resources for M\&E of UWEP activities (Nyonje, Ndunge, \& Mulwa, 2012). Theoretically, there exists a positive relationship between M\&E planning and program performance (Muchelule, Otonde, \& Achayo, 2017). In other words, proper $M \& E$ planning enhances program performance; while improper $M \& E$ planning compromises program performance. This linkage between the study variables can be explained by the theory of change. The theory demonstrates how and why an initiative in form of say a policy or strategy contributes to an intend outcome through a sequence of logically linked events (Vogel, 2012). The theory that has been widely applied in studying M\&E scenarios presupposes that it is possible for program and project managers to assess the progress of their projects, identify areas of weaknesses, report them and then take the necessary corrective actions to ensure that the program or project achieves its intended goals and objectives (Sindayigaya, Ngarambe, \& Nyamweya, 2020).

In Uganda, the Government recognizes the importance of M\&E in enhancing the country's development processes and outcomes. Accordingly, the Government has since enacted the National Policy on Public Sector Monitoring and Evaluation (NPME) whose 
overriding goal is to foster optimal performance of government programs and projects through strengthening and ensuring proper planning and coordination of Government interventions (Uganda Office of Prime Minister, 2011). In spite of the existence of such a framework, the performance of many government programs in Uganda is far from satisfactory, characterized by delays in execution, over-costing of inputs, and delivery of poor-quality services among others, which often lead to poor service delivery outcomes and perpetuation of underdevelopment in the country (Government of Uganda Office of Auditor General, 2019). Uganda Women Entrepreneurship Program (UWEP) is key national service delivery program that seeks to empower women through improving their access to financial services as well as access to knowledge and skills useful in starting and sustainably managing enterprises, add value to their commodities, and market their goods and services (Guloba, Ssewanyana, \& Birabwa, 2017). Its performance in a number of districts in Uganda particularly in Busoga sub region remains decimal, characterized by fund recovery rates of less than $40 \%$ on average (Government of Uganda Office of Auditor General, 2020).

The phenomenon of poor performance of government programs has been extensively researched across the globe in countries such as China (Rui, et al., 2017), Sri Lanka (Santoso \& Gallage, 2019), Oman (Al-Maskari, Al-Maskari, Alqanoobi, \& Kunjumuhammed, 2019), and Saudi Arabia (Elawi, Algahtany, Kashiwagi, \& Sullivan, 2015). Even in Uganda, the poor performance of government programs has been extensively studied and various factors have been attributed to this phenomenon including poor contractor selection and poor contractor monitoring (Byaruhanga \& Basheka, 2017); poor project completion (Opuch, 2016); corruption, poor planning and budgetary indiscipline, weak leadership and motivation, weak oversight and human resource deficiencies implementers without decision-making power, conflict and poor conflict management (Goobi, 2019); and procurement and specification delays, use of poor-quality materials, and poor scheduling (Muzaale, Auriacombe, \& Byaruhanga, 2018) among others. However, the linkage between M\&E planning and program performance more so, using the case study of UWEP remains an empirical grey area. There are even empirical studies albeit very few that have explored the linkage between aspects of M\&E planning and program performance including Phiri (2015) and Mbiti and Kiruja (2015) in Kenya, Niwagaba and Mulyungi (2018) in Rwanda. Therefore, exploring the link between M\&E planning and performance of government programs more so, using a case study of UWEP was very imperative.

Such a study was necessary because maintaining the status-quo regarding the phenomenon of government programs and more so, of UWEP in Busoga sub region, implies that the ability of the program to achieve its objectives will be severely compromised, thereby exacerbating poverty and underdevelopment in the affected region and the country at large. In addition, the findings from the study may inform government efforts aimed at formulating stronger and robust M\&E legal and institutional frameworks for enhancing the performance of UWEP and other government programs. Further still, UWEP Managers may use evidence generated from this study to enhance adherence to the existing M\&E framework, and in turn, enhance performance of UWEP in the affected region. Finally, the scholarly community may use this study's findings in future to further research on the influence of M7E planning on performance of UWEP in other regions of Uganda or Government programs in Uganda and in other countries.

\section{Methods and Procedures \\ 2.1 Research Design}

The study employed a cross-sectional design which entailed collecting survey data on different variables from different individuals at a single point in time. The cross-sectional design was chosen because it enabled the researcher to compare many different variables at the same time. In addition, a mixture of quantitative and qualitative approaches were used in collecting and analyzing data. The mixed methods approach was chosen because it safeguarded the researcher against the disadvantages of using a single approach of data collection and analysis (Denscombe, 2003; Sekaran, 2003; Mugenda \& Mugenda, 2003).

\subsection{Study Population and Sample Size}

The study population constituted UWEP beneficiary groups in the districts of Jinja, Iganga and Kamuli. According to information obtained from Ministry of Gender, Labor and Social Development (MGLSD), at the time of the study, there were a total of 231 UWEP beneficiary groups in the three selected districts. Jinja District had 83 beneficiary groups, Iganga District had 92 beneficiary groups, and Kamuli District had 56 beneficiary groups. Accordingly, approximately 146 UWEP beneficiary groups were sampled and surveyed for purposes of data collection. This sample size was calculated using Yamane's (1967) formula which is given below:

$$
n=\frac{N}{1+N e^{2}}
$$

In this case, $\mathrm{n}$ was sample size, $\mathrm{N}$ was population size, and $e$ was significance level, which was pre-determined at $5 \%$. Thus, the sample size calculation followed the formula above and was determined as follows:

$$
n=\frac{231}{1+231(0.05)^{2}}=146.4
$$

\subsection{Sampling Techniques}

Both probability and non-probability sampling techniques were employed in the study. Under probability sampling, this study employed the technique of proportionate stratified random sampling, which involved categorizing the population into mutually exclusive groups and then randomly drawing samples from each group which are proportionate to the entire population under consideration (Creswell, 2012). Accordingly, 58 beneficiary groups were randomly selected from Iganga District, 52 beneficiary 
groups from Jinja District and 36 beneficiary groups from Kamuli District. Under non-probability sampling, the study employed purposive sampling in selecting respondents to participate in the interviews and in the focus group discussions. Since the program is largely operationally based at sub county level, the key informant interviewees included all officers whose work efforts have a bearing on the performance of UWEP at sub county level in each district. These included: Sub County Council Chairpersons, Sub County Chief Administrators, Sub County Community Development Officers, and Sub County Women Council Chairpersons.

\subsection{Data Collection Methods and Instruments}

Four methods were employed for purposes of data collection including: survey, Key informant interviewing, focus group discussions, and documentary review. This survey method entailed using a standardized set of questions contained in questionnaire and asking a section of the population (in this case, UWEP beneficiaries in Jinja, Iganga and Kamuli Districts) for their views and/or opinions about M\&E planning, and how they influence performance of UWEP as has been guided by research theory (Buckingham \& Saunder, 2004). Key informant interviewing entailed collecting data through asking appropriate individuals questions that were relevant to the subject of investigation and recording their answers. The key informants in this study included UWEP women group leaders, LC 1 Chairpersons, Women Council leaders, Chairperson of the Sub-County Women Council, Community Development Officer, and Sub-County Chiefs in the UWEP catchment areas of the selected districts. One of the perquisites of conducting a successful interview is establishing an environment that encourages respondents to freely express their views (Amin, 2005). All responses were tape-recorded and accompanied by taking notes concerning key phrases and words for purpose of generating followup questions. Focus group discussions entailed assembling small groups of UWEP beneficiaries, presenting them with issues relevant to the subject of investigation and asking them to share their views and opinions on them. This was achieved using a focus group discussion guide. A total of three focus group interviews were conducted, one in each of the three selected districts. Each focus group interview comprised of six participants, and all participants were encouraged to talk and to take their turns talking. The focus group interviews lasted for not more than one and half hours, and the responses were tape-recorded and punctuated with taking of notes during the interviews. Besides relying on primary data, the study also relied on secondary data which was obtained through reading various documents obtained from various sources including books, peer reviewed and non-peer reviewed journal articles, theses and dissertations as well as reports about M\&E attributed to UWEP.

\subsection{Validity and Reliability of Instruments}

To establish validity, two specialists in the field of M\&E attached to the country's Ministry of Gender, Labor and Social Development were solicited and asked to rate the suitability of each items contained in the questionnaire on a scale ranging from $0.0-1.0$. On the basis of this their expert evaluation, only items rated at 0.75 and above were retained in the questionnaire as was recommended by Amin (2005). Beside this, validity of the data collection instrument was further determined through pre-testing the questionnaire prior to the actual data collection exercise. Based on the results of the pre-test, ambiguous items were clarified before finally administering the questionnaire.

Reliability was established through calculating the Cronbach Apha coefficient values for items contained in the survey instrument. Accordingly, the Cronbach's Alpha coefficient values for all items contained in the questionnaire were calculated using the formula of a renowned researcher and author called Yamane. Cronbach Coefficient values for the items contained in the questionnaire ranged from $0.705-0.801$, which were considered of moderate reliability, and therefore suitable for purposes of collecting data.

\subsection{Data Processing and Analysis}

Two forms of data were collected for the purpose of achieving objectives of this study - quantitative and qualitative data. In order to determine how each predictor variable influences the outcome variable, the researcher formulated index values of items representing each predictor variables and the outcome variable. Using these index values, the researcher then employed the $\mathrm{Bi}$ variate Pearson's correlation analysis technique in order to establish whether indeed the predictor variables influence the outcome variable as highlighted in the study objectives. All the analysis was conducted using tools such as Ms Excel and Statistical Package for Social Scientists (SPSS).

Qualitative data was analyzed based on Creswell (2005) qualitative analysis guidelines. First, emerging themes from the data were identified. Secondly, all redundant information in the data were eliminated. Thirdly, themes were classified into categories, and categories were classified into sub-categories. Finally, the categories and sub-categories were integrated into themes that describe how M\&E practices influence performance of UWEP in the three selected districts of Busoga sub region-Jinja, Iganga and Kamuli.

\section{Results}

Out 146 targeted survey respondents, 135 successfully completed the survey representing a response rate of $92.4 \%$. Among key informants, 13 out of the targeted 36 respondents successfully completed the interviews, which represents a response rate of $36.1 \%$. Finally, the research targeted to conduct three FGDs, one from each of the three districts under study; however, two were successfully conducted, which represents are response rate of $66.7 \%$. Overall, the response rate among survey respondents was considered adequate for reporting and analysis going by the guidelines of (Mugenda and Mugenda, 2005). 


\subsection{Perceived Performance of UWEP in Busoga, Uganda}

The outcome variable of the study was performance of UWEP. The variable was assessed in terms of the program's goals and objectives which are enhancing women's welfare through improving their access to financial services as well as access to knowledge and skills for beginning and sustainably managing enterprises, adding value to their commodities, and marketing their goods and services (Guloba, Ssewanyana, \& Birabwa, 2017). The study sought to determine how far respondents agreed or disagreed with 4 statements on the performance of UWEP in the selected districts. Responses to these items were rated on a scale of five points starting from $1=$ strongly disagree, $2=$ disagree, $3=$ neutral, $4=$ agree to $5=$ strongly agree. The descriptive statistics of means and standard deviations were employed in analyzing the responses. Table 1 in the appendix summarizes findings in this regard.

One of the indicators of UWEP performance was the extent to which UWEP beneficiaries are opening up more enterprises compared to non-beneficiaries. The findings in Table 1 in the appendix indicate a mean of 2.95 and corresponding standard deviation of 1.03. The mean value was found to be less than the threshold of agree (3.00), which means that, on average, most respondents disagreed with the statement.

Survey respondents were also asked to indicate how far they agree or disagree with the statement that "UWEP beneficiaries are managing their enterprises better than non-beneficiaries". The findings in Table 1 in the appendix revealed a mean score of 2.86 and the corresponding standard deviation score of 1.12. The mean score value was found lying below the threshold of agree (3.00), which means that, on average, most respondents did not agree with the statement.

Performance of UWEP was also assessed in terms of the extent to which UWEP beneficiaries have better access to markets for their products than non-beneficiaries. Respondents 'opinions reflected in Table 1 in the appendix show a mean response score of 2.76 and a corresponding standard deviation value of 1.41. The mean score was found less than the threshold of 3.00, which implies that, on average most respondents disagreed with the statement.

The final item used to measure performance of UWEP was the extent to which UWEP beneficiaries have better access to value addition innovations relative to non-beneficiaries. The findings in Table 1 in the appendix indicated a mean score of 2.65 and a corresponding standard deviation value of 1.27. The value was found to be lower than the threshold value of agree (3.00), which implied that, on average, most respondents felt that UWEP beneficiaries did not have better access to value addition innovations compared to non-beneficiaries. Generally, the standard deviation scores corresponding to the mean scores of the four items were all found to be small, which implied that most actual responses did not significantly differ from the expected responses.

The survey findings were consistent with some of the findings generated through interviewing key informants. Key informants were asked to comment about the performance of Uganda Women's Entrepreneurship Program in their district. Some of their responses portrayed unsatisfactory performance of the program. For instance, from one of the key informant responses, it emerged that inability of a considerable portion of UWEP beneficiaries to start income-generating in itself was a reflection of the program's failure. This is what one of the key informants had to say:

One of the objectives of UWEP is to enable women start their own income-generating enterprises. Prior to joining UWEP, women are equipped with a variety of knowledge and skills including being able to identify and start income generating enterprises. However, through experience, we have seen that only very few of these women who received this training have been able to effectively use this knowledge and start their own enterprises (Key Informant D).

In addition, inability of UWEP beneficiaries to access markets was also perceived a failure of the program as is contained in the following key informant confession:

Access to markets is still a major challenge for beneficiaries of UWEP who are involved in business. We have encouraged and supported women to engage in income-generating activities. For instance, in my area, many women are involved in growing maize. Unfortunately, during harvest time they are unable to sell off their maize because they are not in position to find buyers, something which demoralizes them so much (Key Informant $\mathrm{H}$ ).

Overall, the findings of the study revealed poor and unsatisfactory performance of UWEP in the three districts of Jinja, Iganga and Kamuli. The poor performance of Government programs in Uganda has been well documented (Government of Uganda Office of Auditor General, 2019). In addition, a recent Government of Uganda Office of Auditor General (2020) also alluded to decimal performance of the program particularly in Busoga sub-region. Clearly, the findings of the study were consistent with the above findings. The next three section presents the study findings relating M\&E planning and performance of UWEP in Busoga, Uganda.

\subsection{Perceived State of M\&E Planning under UWEP}

In order to ascertain the state of M\&E planning in UWEP, respondents were asked to indicate the extent to which they agreed or disagreed with a number of statements measuring the construct. The state of M\&E planning in UWEP was assessed using 8 statements that focused on thematic areas of: setting clear M\&E goals, participation in setting goals M\&E goals, budgeting for $M \& E$ activities, and setting timelines for $M \& E$ activities. The responses to these items were rated on a likert scale of 5 points ranging from $1=$ strongly disagree to $5=$ strongly agree. Table 2 in the appendix presents the findings in relation with the state of M\&E planning under UWEP. 
One of the items employed for assessing how well monitoring and evaluation planning was conducted under UWEP was the extent to which management sets clear goals for monitoring and evaluation of UWEP activities. The other item was the extent to which beneficiaries understand the goals for monitoring and evaluation of UWEP activities. The mean response scores for the respective items (2.26 and 2.21), and these were less than the threshold for agreeing with a particular item (3.00). In this case, most respondents disagreed with both items, suggesting that management does not set clear goals for monitoring and evaluation of UWEP activities, and most of them do not understand the goals for monitoring and evaluation of UWEP activities.

The other set of items used for assessing the extent to which M\&E planning is well conducted under UWEP included: the extent to which beneficiaries participate in formulating goals for monitoring and evaluation of UWEP activities, and the extent to which management seeks opinions of beneficiaries when formulating goals for M\&E of UWEP activities. From Table 2 in the appendix, the respective mean scores for these items are 2.95 and 2.67 both of which are below the threshold for agreeing with a particular item (3.00). Clearly, most respondents disagreed with both items, suggesting that most beneficiaries do not participate in formulating goals for monitoring and evaluation of UWEP activities, and management does not seek their opinions when formulating goals for M\&E of UWEP activities.

The other set of items used for assessing the extent to which M\&E planning is well conducted comprised the extent to which management budgets for monitoring and evaluation of UWEP activities, and the extent to which management allocates sufficient resources for monitoring and evaluation of UWEP activities. The respective mean scores for these items are 3.05 and 2.42 . The former value is slightly above the threshold for agreeing with a particular item (3.00), while the latter value is below the threshold for agreeing with a particular item (3.00). Since the results reveal that most respondents marginally agreed the first item and disagreed with the second item, it means that most of them are of the view that management budgets for monitoring and evaluation of UWEP activities, but it does not allocate sufficient resources for monitoring and evaluation of UWEP activities.

The final set items used for assessing the extent to which M\&E planning comprised of whether management sets timelines for monitoring and evaluation of UWEP activities, and whether management sets realistic timelines for monitoring and evaluation of UWEP activities. The mean scores for the two items are 2.35 and 2.58 respectively. These mean scores are less than the threshold for agreeing with a particular item (3.00). These findings imply that most respondents are of the view that management does not set timelines for monitoring and evaluation of UWEP activities, and management does not set realistic timelines for monitoring and evaluation of UWEP activities. The standard deviation scores corresponding to all items assessing M\&E planning were in the rage of $1.03-1.24$. These figures were generally small, implying that the responses were not very far from the mean.

In addition, some of the findings generated from the key informant interviews and focus group discussions were consistent with findings generated from survey findings. For instance, when key informants were asked whether they were satisfied with the state of monitoring and evaluation planning under the UWEP, one of the key informants decried the lack of involvement in setting of M\&E goals and the failure to budget for M\&E activities under UWEP:

In management of programs or projects, planning is very important ingredient for success. However, planning for monitoring and evaluation of UWEP activities is not given its due importance. The specific features of the program that we are supposed to monitor and evaluate are not clearly communicated to us. We are not even adequately involved in the planning process. I am not even sure whether adequate funds for monitoring and evaluation of activities are provided for in the budget (Key Informant B).

When asked for their views on the state of planning for monitoring and evaluation activities under the Uganda Women's Entrepreneurship Program, this is what one of the focus group discussants had to say:

Honestly, it is my first time I am hearing about planning for monitoring and evaluation of UWEP activities. Generally, we are never involved so we never get to know about planning for monitoring and evaluation of our activities as beneficiaries, how it is done, when it is done, and who does it (Female FGD participant).

Overall, the findings from the survey, key informant interviews and focus group discussions revealed a poor and undesirable state of M\&E planning under UWEP which was characterized by failure to set clear M\&E goals, non-participation in setting M\&E goals, failure to budget for M\&E activities, and failure to set timelines for M\&E activities. The poor state of M\&E planning could compromise the performance of UWEP. The following sub section presents findings which establish whether M\&E planning statistically influences the performance of UWEP in Busoga, Uganda.

\subsection{Influence of ME Planning on Performance of UWEP in Busoga, Uganda}

The second step taken to achieve the study objective was that items measuring the state of M\&E planning and the level of UWEP performance were transformed into two respective index variables using the Compute Variable Dialog Window in SPSS. These two index variables were then subjected to a Pearson's Correlation test in order to determine the statistical influence of M\&E planning on the performance of UWEP in Busoga sub-region. The test was conducted under the following hypothesis: there is no 
significant influence of M\&E planning on the performance of UWEP in Busoga sub region. The results are summarized in Table 3 in the appendix.

The findings in Table 3 in the appendix indicated a correlation coefficient of 0.755 and a corresponding probability value that was less than 0.05 . The correlation coefficient was found to be positive suggesting that better M\&E planning that was characterized by setting clear M\&E goals, participation in setting M\&E goals, budgeting for M\&E activities, and setting timelines for M\&E activities was associated with better performance of UWEP in terms of beneficiaries' ability to open up new enterprises, manage enterprises, access markets for their products, and access value addition innovations. On the other hand, poor M\&E planning that was characterized by failure to set clear M\&E goals, non-participation in setting M\&E goals, failure to budget for M\&E activities, and failure to set timelines for M\&E activities, was associated with poor performance of UWEP in terms of beneficiaries' ability to open up new enterprises, manage enterprises, access markets for their products, and access value addition innovations. The corresponding probability value was less than 0.05 , which implied that the hypothesis that: there is no significant influence of $\mathrm{M} \& \mathrm{E}$ planning on the performance of UWEP in Busoga sub-region was rejected. Instead, it was concluded that there is a significant influence of M\&E planning on the performance of UWEP in Busoga sub-region.

The findings above were supported by data derived from key informant interviews and FGDs. For instance, one of the key informants decried the lack of adequate planning for M\&E activities under UWEP and how this had compromised the performance of the program. She had this to say:

$M \& E$ is an important factor for ensuring successful performance of projects. UWEP is failing to achieve its intended objectives in this area because the function of monitoring and evaluation under this program has been given lip service. There is hardly any deliberations about monitoring and evaluation at the strategic level. As a result, we lack an organized system that can feed us with accurate and timely information that we can use to identify program weaknesses or failures, and suggest appropriate corrective actions (Key Informant F).

In one of the FGDs, a participant was dismayed about the lack of budgeting for M\&E under UWEP and that this had affected its performance. He had this to say:

UWEP cannot achieve its objectives if the project activities of beneficiaries are not monitored or even evaluated. I and my group members have never seen any official come to inspect our project activities, and I think this is very bad because we are not able to receive the necessary and appropriate guidance. I took up this matter some time back with concerned program officials, and I was told it is not possible to engage in meaningful monitoring and evaluation because of the peanut allocations made during the budgeting process (Female FGD participant).

Clearly, both quantitative and qualitative findings showed that there existed a poor state of M\&E planning under UWEP and that this was statistically associated with poor performance of the program in Busoga, Uganda.

\section{Discussion}

The objective of this study was to examine the influence of M\&E planning on the performance of UWEP in Busoga sub-region. From the findings, it emerged that the state of M\&E planning under UWEP was generally poor characterized by improper M\&E planning characterized by failure to set clear M\&E goals, identify sufficient resources for M\&E activities, establish M\&E timelines, and ensure participation. In addition, based on the Pearson's Correlation coefficient, it emerged that M\&E planning significantly influenced the performance of UWEP in a positive way in the three selected districts of Busoga Sub-region $(r=0.755 ; p<0.05)$. The quantitative findings were supported by the qualitative findings in this regard.

The above findings were in line with earlier empirical studies by Phiri (2015) who studied the influence of M\&E on performance of two projects executed by African Virtual University in Kenya, and found that monitoring planning significantly affected the performance of the projects executed by African Virtual University in Kenya. They were also in support of Niwagaba and Mulyungi (2018) who found a significant positive relationship between M\&E planning and the performance of projects in Rwanda using a case of selected non-government organizations in Gasabo District. The findings further supported earlier findings by Mbiti and Kiruja (2015) who found that planning of M\&E plays an important positive role in the performance of State Corporations in Kenya using Kenya Meat Commission (KMC) as the case study. The study findings suggest that improving the state of M\&E planning may enhance the performance of UWEP in Busoga sub region of Uganda. From the theory change, M\&E planning enables program managers to assess the progress of their projects, identify areas of weaknesses, report them and then take the necessary corrective actions to ensure that the program achieves its intended goals and objectives (Sindayigaya, Ngarambe, \& Nyamweya, 2020).

However, the findings of the study ought to be read and interpreted cautiously owing to the limitations associated with them. First, the study was largely based on the subjective perceptions of UWEP beneficiaries and officials with a direct managerial bearing on the program in the selected districts. Such data may not accurately reflect the M\&E practices under UWEP nor its performance. Secondly, the study was largely based on a cross-sectional and descriptive research design. As such, it could not establish a real cause and effect relationship between M\&E practices and performance of UWEP in the three selected districts of Busoga sub- 
region. Finally, the study was based on data generated from 3 out of 11 districts in Busoga sub region. As such, its findings may only be applicable or generalizable to the three selected districts of Jinja, Iganga and Kamuli.

\section{Conclusion}

It is very clear that the state of M\&E planning is an important positive factor in the performance of government programs more so, the Uganda Women's Entrepreneurship Program in Busoga sub region. Thus, improving the state of M\&E planning would enhance the performance of UWEP in the three selected districts of Busoga Sub-region. The study recommends that UWEP Managers should improve the state of M\&E planning under the program by:

- $\quad$ Setting clear and understandable goals for monitoring and evaluation of UWEP activities.

- Allowing UWEP beneficiaries to participate in the formulation of M\&E goals.

- Allocating sufficient budgetary resources for monitoring and evaluation of UWEP activities.

- $\quad$ Setting realistic timelines for monitoring and evaluation of UWEP activities.

\section{Appendix}

Table 1: Respondents' views on performance of UWEP

\begin{tabular}{llccc}
\hline Items on UWEP Performance & N & Min. & Max. & $\begin{array}{c}\text { Mean } \\
\text { Std. } \\
\text { Dev. }\end{array}$ \\
\hline $\begin{array}{l}\text { UWEP beneficiaries are opening up more enterprises than non- } \\
\text { beneficiaries }\end{array}$ & 135 & 1 & 5 & 2.95 \\
$\begin{array}{l}\text { UWEP beneficiaries are managing their enterprises better than non- } \\
\text { beneficiaries }\end{array}$ & 135 & 1 & 5 & 2.86 \\
$\begin{array}{l}\text { UWEP beneficiaries have better access to markets for their products } \\
\text { than non-beneficiaries }\end{array}$ & 135 & 1 & 5 & 2.76 \\
$\begin{array}{l}\text { UWEP beneficiaries have better access to value addition innovations } \\
\text { than non-beneficiaries }\end{array}$ & 135 & 1 & 5 & 2.65 \\
\hline
\end{tabular}

Table 2: State of M\&E planning under UWEP

\begin{tabular}{|c|c|c|c|c|c|}
\hline Items on state of M\&E planning under UWEP & $\mathbf{N}$ & Min. & Max. & Mean & Std. Dev. \\
\hline $\begin{array}{l}\text { Management sets clear goals for monitoring and evaluation of } \\
\text { UWEP activities }\end{array}$ & 135 & 1 & 5 & 2.26 & 1.10 \\
\hline $\begin{array}{l}\text { Beneficiaries understand the goals for monitoring and } \\
\text { evaluation of UWEP activities }\end{array}$ & 135 & 1 & 5 & 2.21 & 1.08 \\
\hline $\begin{array}{l}\text { Beneficiaries participate in formulating goals for monitoring } \\
\text { and evaluation of UWEP activities }\end{array}$ & 135 & 1 & 5 & 2.95 & 1.03 \\
\hline $\begin{array}{l}\text { Management seeks opinions of beneficiaries when formulating } \\
\text { goals for M\&E of UWEP activities }\end{array}$ & 135 & 1 & 5 & 2.67 & 1.16 \\
\hline $\begin{array}{l}\text { Management budgets for monitoring and evaluation of UWEP } \\
\text { activities }\end{array}$ & 135 & 1 & 5 & 3.05 & 1.24 \\
\hline $\begin{array}{l}\text { Management allocates sufficient budget resources for M\&E of } \\
\text { UWEP activities }\end{array}$ & 135 & 1 & 5 & 2.42 & 1.10 \\
\hline $\begin{array}{l}\text { Management sets timelines for monitoring and evaluation of } \\
\text { UWEP activities }\end{array}$ & 135 & 1 & 5 & 2.35 & 1.07 \\
\hline $\begin{array}{l}\text { Management sets realistic timelines for monitoring and } \\
\text { evaluation of UWEP activities }\end{array}$ & 135 & 1 & 5 & 2.58 & 1.21 \\
\hline
\end{tabular}

Table 3: Correlation between M\&E planning and performance of UWEP

\begin{tabular}{llll}
\hline & & M\&E planning & UWEP performance \\
\hline M\&E planning & Pearson's correlation & 1 & $.755^{* *}$ \\
& Sig. (2-tailed) & & .000 \\
& $N$ & 135 & 135 \\
UWEP performance & Pearson's correlation & $.755^{* *}$ & \\
& Sig. (2-tailed) & .000 & 1 \\
& $N$ & 135 & 135 \\
\hline
\end{tabular}

Notes: ** Significant at 0.05 


\section{Bibliography}

Al-Maskari, A., Al-Maskari, M., Alqanoobi, M., \& Kunjumuhammed, S. (2019). Internal and external obstacles facing medium and large enterprises in Rusayl Industrial Estates in the Sultanate of Oman. Journal of Global Entrepreneurship Research, 9(1), 1 -20 .

Amin, E. M. (2005). Social science research: Conception, methodology and analysis. Kampala: Makerere University Printery. Biwott, T., Egesah, O., \& Ngeywo, J. (2017). Importance of monitoring and evaluation in the sustainability of constituency development fund projects in Kenya. International Journal of Management \& Social Sciences, 7(1), 45 - 51.

Buckingham, A., \& Saunder, P. (2004). The survey options workbook. London: Polity.

Byaruhanga, A., \& Basheka, B. C. (2017). Contractor monitoring and performance of road infrastructure projects in Uganda: A management model. Journal of Building Construction and Planning Research, 5, 30 - 44.

Callahan, M. (2015). The busy person's guide to measuring and improving program performance. London.

Creswell, J. W. (2012). Research design: Quantitative, qualitative, and mixed methods. Thousand Oaks: CA: Sage.

Denscombe, M. (2003). The good research guide for small-scale research projects (2nd ed.). Buckingham: Open University Press. Elawi, G. S., Algahtany, M., Kashiwagi, D., \& Sullivan, k. (2015). Major factors causing construction delays in Mecca. Journal for the Advancement of Performance Information and Value, 7(1), 1 - 11.

Goobi, R. (2019). From paper to practice: Implementation of Uganda's industrialisation agenda. Kampala: Friedrich-EbertStiftung.

Government of Uganda. (2015). Second National Development Plan: 2015/16 - 2019/20. Kampala.

Government of Uganda Office of Auditor General. (2019). Annual Performance Report 2018. Kampala: Office of Auditor General. Government of Uganda Office of Auditor General. (2020). Annual Performance Report 2019. Kampala: Office of Auditor Genera. Guloba, M., Ssewanyana, S., \& Birabwa, E. (2017). Rural women entrepreneurship in Uganda : A synthesis report on policies, evidence, and stakeholders. Kampala: Economic Policy Research Center.

Kusek, J. Z., \& Rist, R. C. (2004). A handbookfor development practitioners: Ten steps to a result-based monitoring and evaluation system. Washington, D.C: The World Bank.

Mark, K., \& Pfeiffer, J. R. (2011). Monitoring and evaluation in the United States Government: An overview. Washington: The World Bank.

Mbiti, V. M., \& Kiruja, D. E. (2015). Role of monitoring and evaluation on performance of public organization projects in Kenya: A case of Kenya Meat Commission. International Journal of Innovative Development \& Policy Studies, 3(3), 12 - 27.

Muchelule, Y., Otonde, M. G., \& Achayo, M. S. (2017). Influence of monitoring and evaluation onperformance of constituency development fundprojects In Kajiado East Sub-County, Kenya. The International Journal of Management Science and Information Technology, 23, 12 - 26.

Mugenda, O., \& Mugenda, A. (2003). Research Methods, Quantitative and Qualitative Approaches. Nairobi: ACT.

Muzaale, T., Auriacombe, C., \& Byaruhanga, A. (2018). Performance of road infrastructure projects in Uganda: A procurement approach. The Ugandan Journal of Management and Public Policy Studies, 15(1), 1 - 22.

Niwagaba, H., \& Mulyungi, D. P. (2018). Influence of Monitoring and Evaluation Planning on Project Performance in Rwanda: A Case of Selected Non-Governmental Organizations in Gasabo District. European Journal of Business and Strategic Management, $3(8), 1-16$.

Nyonje, R. O., Ndunge, K. D., \& Mulwa, A. S. (2012). Monitoring and evaluation of projects and programs. A handbook for students and practitioners. Nairobi: Aura Publishers .

Opuch, C. (2016). Local contractors' performance management and project completion in construction industry: A case study of road maintenance contractors under UNRA Lira Station. Kampala: Unpublished MBA Project, Uganda Technology and Management University.

Phiri, B. (2015). Influence of monitoring and evaluation on project performance: A case of African Virtual University, Kenya. Nairobi: University of Nairobi.

Pride, W., \& Ferell, O. C. (2003). Monitoring and evaluation. Boston: Houhton Mifflin.

Rui, Z., Peng, F., Ling, K., Chang, H., Chen, G., \& Zhou, X. (2017). Investigation into the performance of oil and gas projects. Journal of Natural Gas Science and Engineering, 38, 12-20.

Santoso, D. S., \& Gallage, P. G. (2019). Critical factors affecting the performance of large construction projects in developing countries. Journal of Engineering, Design and Technology, 18, 531 - 556.

Schoenefeld, J. J., Schulze, K., Hildén, M., \& Jordan, A. J. (2019). Policy monitoring in the EU: The impact of institutions, implementation, and quality. Polit Vierteljahresschr, 60, 719 - 741.

Sekaran, U. (2003). Research methods for business: A skill-buiding approach (4th ed.). New York: John Wiley \& Sons.

Sindayigaya, G. J., Ngarambe, P., \& Nyamweya, M. N. (2020). Monitoring and evaluation and institutional performance. International Journal of Scientific and Research Publications, 10(11), 367 - 377.

Uganda Office of Prime Minister. (2011). National Policy on Public Sector Monitoring and Evaluation. Kampala.

Vogel, I. (2012). Review of the use of "Theory of Change” in international development. London: DFID.

Yamane, T. (1967). Statistics: An Introductory Analysis. New York: Harper and Row. 


\section{AUTHORS}

Mbaziira Hassan, Bsc Quantitative Economics, Master of Business Administration, Monitoring, Evaluation, Accountability \& Learning Expert; Uganda Women Entrepreneurship Programme. Email: hassanmbaziira@ gmail.com. Contact: +256-703-859320

Correspondence Author. Dr. Naomi Njoroge Nduta, Department of Social and Development Studies, School of Social Sciences, Mount Kenya University. Email: ndutanjoroge600@gmail.com 